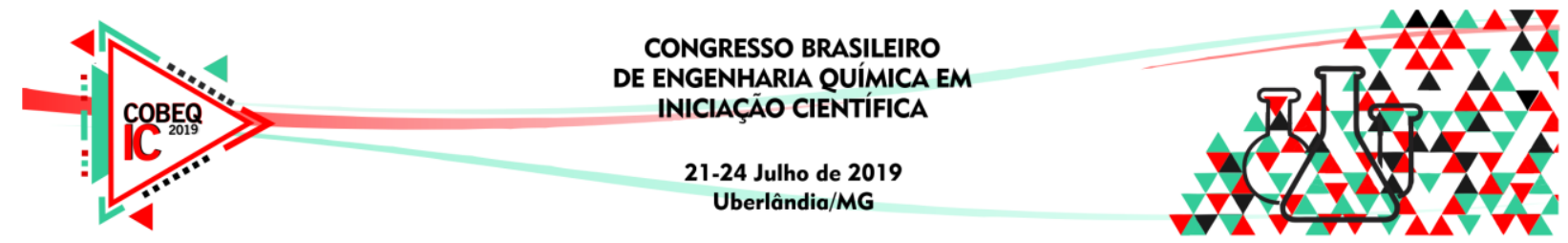

\title{
AVALIAÇÃO DA DESPOLIMERIZAÇÃO DO POLITEREFTALATO DE ETILENO (PET) E A PREPARAÇÃO DE NOVOS POLIOIS
}

\author{
D. P. R. ARAÚJO' ${ }^{1}$, L. V. ARAÚJO' ${ }^{1}$, R. V. GOMES ${ }^{1}$, B. N. MELO ${ }^{1}$, R. C. S. ARAÚJO² \\ ${ }^{1}$ Universidade Federal do Espírito Santo, CEUNES, Departamento de Ciências Naturais \\ ${ }^{2}$ Universidade Federal de Minas Gerais, ICEx, Departamento de Química \\ E-mail para contato: breno.melo@ufes.br
}

\begin{abstract}
RESUMO - A crescente produção e utilização do Politereftalato de Etileno (PET) trouxe um grande problema ambiental associado ao seu descarte inadequado. A sua reciclagem sistemática é uma das soluções para minimizar este problema. Neste trabalho é proposta a reciclagem química do PET a partir da glicerólise. As reações de despolimerização foram realizadas a $240^{\circ} \mathrm{C}$ em concentrações de 10 , 20, 30, 40, 50, e 60\% em massa de PET no glicerol, na presença de catalisador, nos intervalos de 30, 60 e $90 \mathrm{~min}$. Os materiais finais obtidos foram caracterizados por espectroscopia na região de infravermelho (FTIR), por análise termogravimétrica TGA, teor de hidroxilas $(\mathrm{OH})$ e acidez. $\mathrm{O}$ glicerol se mostrou um bom solvente, propiciando uma despolimerização em menores tempos de reação. A estabilidade térmica aumenta em função do conteúdo de PET e do tempo de reação. Os espectros de FTIR confirmaram a eficiência na formação de novos polióis, devido ao surgimento e supressão de bandas características dos materiais de partida, gerando um poliéster polihidroxilado. Com o aumento no tempo de reação, os polióis apresentaram diminuição no teor de $\mathrm{OH}$ e aumento na acidez. Contudo, foi possível despolimerizar até $60 \%$ de PET em glicerol e formular uma classe de polióis ésteres para futuras aplicações na síntese de polímeros.
\end{abstract}

\section{INTRODUÇÃO}

O politereftalato de etileno (PET) destaca-se entre os plásticos sintéticos por ser um dos termoplásticos mais produzidos no mundo. Suas características e seu baixo custo de produção o tornam muito bem aceito no mercado tendo como principais aplicações as indústrias têxtil e de embalagens. No Brasil são produzidas cerca de 550 mil toneladas de PET por ano (ABIPET, 2016) do qual $71 \%$ é destinado ao mercado de embalagens com $32 \%$ tendo como fim a produção de garrafas carbonatadas, segundo Romão et al. (2009). No entanto, seu vasto consumo e o descarte inapropriado criaram sérios problemas ambientais. Mesmo reciclando $51 \%$ de PET (ABIPET, 2016), diante do valor que é produzido, muito material acaba 


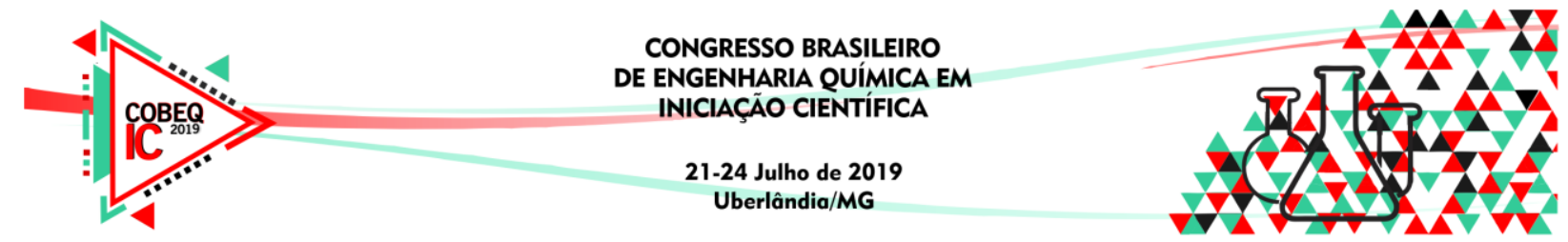

sobrecarregando aterros, poluindo matas, rios e oceanos. Por ser um plástico com lento processo degradativo, é de suma importância o desenvolvimento de métodos para sua reciclagem (Almeida et. al., 2013). Felipe (2014) apresentou a possibilidade de usar o PET na fabricação de telhas sustentáveis. Santos et al. (2018) estudou o processo de hidrólise química deste material em meio alcalino para recuperação do ácido tereftálico.

A reciclagem química ou terciária conduz à despolimerização total ou parcial do PET aos seus monômeros de partida ou oligômeros, respectivamente. Esta transformação pode ser realizada pelos processos de hidrólise, glicólise, metanólise e aminólise (Fonseca et al., 2014). A glicólise, em especial, envolve a utilização de um diol em temperaturas moderadamente altas, catalisada por acetatos metálicos. A reação passa a ser denominada glicerólise se o solvente empregado for o glicerol, um triol que tem mostrado eficiência neste processo.

Este trabalho tem por objetivo avaliar a modificação química do PET via glicerólise utilizando um catalisador básico para a geração de novos polióis poliésteres.

\section{EXPERIMENTAL}

Os materiais utilizados neste trabalho foram o glicerol P.A (VETEC) e garrafas PET pós-consumo. As garrafas foram lavadas e secas previamente e, por fim, picotadas, com auxílio de tesoura, até se obter pequenos quadrados de aproximadamente $1 \mathrm{~cm}$ de aresta.

As despolimerizações foram realizadas em um béquer de $250 \mathrm{~mL}$ (reator) via glicerólise, nos conteúdos de 10, 20, 30, 40, 50 e $60 \%$ m/m de PET em relação ao glicerol. A reação foi acompanhada em 3 tempos: i) $30 \mathrm{~min}$; ii) $60 \mathrm{~min}$ e iii) $90 \mathrm{~min}$. As amostras foram denominadas conforme o teor de PET e o tempo de reação, por exemplo, 1030, correspondendo ao teor $10 \%$ de PET reagido por $30 \mathrm{~min}$.

Primeiramente o glicerol e o catalisador foram pesados diretamente no reator. O PET foi pesado separadamente. A mistura (glicerol/cat.) foi mantida sob agitação e aquecimento, utilizando um agitador mecânico (Fisatom, modelo 713D) e manta aquecedora. Ao atingir a faixa de 220 a $240^{\circ} \mathrm{C}$ foi adicionado o PET pesado e iniciou-se a cronometragem do tempo.

\subsection{Caracterização por Espectroscopia de Absorção na Região do Infravermelho via ATR (Attenuated Total Reflectance)}

As amostras foram analisadas por Espectroscopia de Absorção na Região do Infravermelho via ATR, realizadas em condições ambientes, utilizando o espectrômetro CARY 630 da Agilent Technologies equipada com célula de diamante.

\subsection{Determinação do Teor de Hidroxilas e Acidez}






Os polióis foram analisados quanto ao teor de hidroxilas conforme a norma ASTM D4274-05, método de ftalação. Para o número de acidez foi utilizado a ASTM D4662-03.

Para o teor de hidroxilas misturou-se aproximadamente 1,0g de amostra em 25,0 mL de uma solução de anidrido ftálico em piridina, dentro de um balão de $50 \mathrm{~mL}$. Após $1 \mathrm{~h}$ sob refluxo brando encerrou-se o aquecimento. Reestabelecida a temperatura ambiente, o condensador foi lavado com $5 \mathrm{~mL}$ de água destilada. Em seguida, foi retirada uma alíquota de $5 \mathrm{~mL}$, na proporção de 1:6, para titulação $\mathrm{com} \mathrm{NaOH} 0,5 \mathrm{~mol} / \mathrm{L}$, indicando o ponto final com fenolftaleína. $\mathrm{O}$ teor de $\mathrm{OH}$ foi calculado a partir da Equação 1.

$$
\text { Teor de } O H=\frac{(B-A) * C * 56,1}{\text { massa da amostra }}
$$

Onde: B: volume gasto no branco; A: volume gasto na amostra; $\mathbf{C}$ : concentração da base.

Para o número de acidez foi dissolvido aproximadamente 1,0g da amostra em 50,0 mL de uma solução tolueno e etanol 1:1, em um erlenmeyer de $250 \mathrm{~mL}$. Em seguida titulou-se a solução com $\mathrm{KOH}$ hidroalcóolico $0,1 \mathrm{~mol} / \mathrm{L}$, utilizando fenolftaleína como indicador. Com o emprego dos mesmos parâmetros anteriores, o número de acidez foi obtido pela equação 2 .

$$
\text { No de acidez }=\frac{(A-B) * C * 56,1}{\text { massa da amostra }}
$$

\subsection{Análise Térmica - TGA}

As amostras foram analisadas por termogravimetria utilizando uma termobalança TA Instruments TGA 745 Q50, em atmosfera de $\mathrm{N}_{2}$ com fluxo de $60 \mathrm{~mL} / \mathrm{min}$ e taxa de aquecimento de $10^{\circ} \mathrm{C} / \mathrm{min}$, em cadinho de platina. Massa de amostra em torno de $10 \mathrm{mg}$.

\section{RESULTADOS E DISCUSSÕES}

O processo da glicerólise do PET seguiu um padrão de despolimerização nas amostras. Aos 30min de reação, o polímero se fragmenta, precipitando um sólido esbranquiçado que pode ser o ácido tereftálico, reagente principal da formação do PET. À medida que o tempo de reação aumenta, há a recombinação do precipitado, formando um fluido mais viscoso. A figura 1 apresenta a despolimerização no teor de $10 \%$.

Figura 1 - Fotografia do Processo Glicerólise nos Tempos de 30, 60 e 90 min de reação no teor de $10 \%$ de PET (da esquerda para a direita).
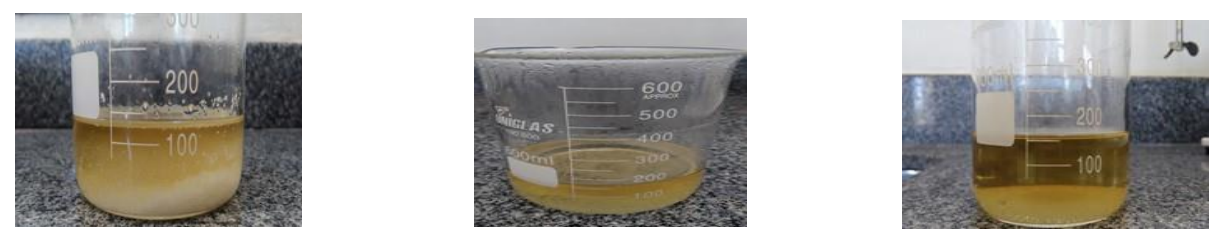


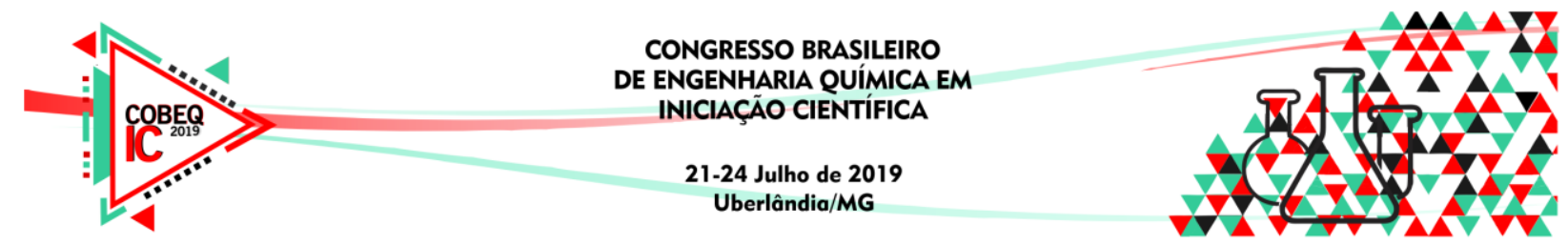

Vale ressaltar que o procedimento conduziu a um arranjo de ligações cruzadas gerando um novo polímero visto que, o glicerol é um poliol trihidroxilado e garante ao menos uma ligação na sua hidroxila secundária. Nota-se também uma mudança gradativa da coloração à medida que o tempo de reação passa e quando o teor de PET aumenta, ou seja, a coloração translúcida do glicerol passa para a coloração castanha escura. O escurecimento deve-se ao efeito da degradação térmica e oxidativa do polímero, já que o procedimento não foi realizado sob atmosfera inerte.

As análises por FTIR mostraram o surgimento de bandas características de éster em $1.730 \mathrm{~cm}^{-1}, 1300 \mathrm{~cm}^{-1}$ e $1.100 \mathrm{~cm}^{-1}$. Estas bandas aumentam gradativamente a cada nova porcentagem de PET adicionada e também com o passar do tempo de reação. A tabela 1 abaixo reúne as principais bandas observadas e suas atribuições. Na figura 2, mostrada em seguida, foram apresentados os espectros das amostras nos teores de $10 \%$ e $60 \%$ de PET.

Tabela 1 - Bandas observadas nos espectros de absorção na região do infravermelho e suas atribuições para a despolimerização do PET por glicerólise.

\begin{tabular}{ccc}
\hline Número de Onda $\left(\mathbf{c m}^{-1}\right)$ & Grupo Funcional & Atribuição \\
\hline $\mathbf{3 . 4 2 9}$ & $-\mathrm{C}-\mathrm{O}-\mathrm{H}$ & $\begin{array}{c}\text { Deformação axial de O-H em ligação de hidrogênio } \\
\text { intermolecular }\end{array}$ \\
\hline $\mathbf{3 . 0 7 5}$ & Ar-H, conj. COOR & Deformação axial de C-H de aromático \\
\hline $\mathbf{2 . 9 5 1}$ & C-H & Vibrações de deformação axial \\
\hline $\mathbf{1 . 7 1 4}$ & -CO-OR, conj. Ar & Vibrações de deformação axial de ésteres acrílicos \\
\hline $\mathbf{1 . 2 6 4}$ & -CO-O-C- & Vibrações de deformação axial de C-O \\
\hline $\mathbf{1 . 1 0 1}$ & O-C-C & Deformação axial simétrica \\
\hline $\mathbf{7 2 4}$ & Ar-H & Deformação angular fora do plano \\
\hline
\end{tabular}

Figura 2 - Espectros de FTIR dos polióis formulados nos teores de 10\% e $60 \%$ de PET.


$\mathrm{O}$ teor de $\mathrm{OH}$ e o número de acidez estão apresentados na figura 3 abaixo. Observa-se que o teor de hidroxilas diminui e a acidez aumenta com o decorrer do tempo. Destaca-se que o glicerol de partida apresenta teor de hidroxilas de $440 \mathrm{mg} \mathrm{KOH} / \mathrm{g}$ e que no meio de reação os novos polióis apresentam valores menores, chegando a $84 \mathrm{mgKOH} / \mathrm{g}$ para o poliól 5090. 


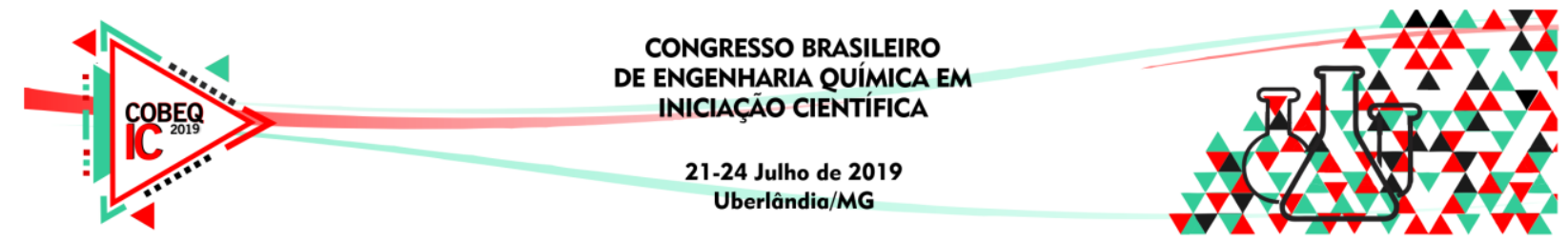

Figura 3 - Variação do teor de hidroxilas e da acidez dos polióis formulados.

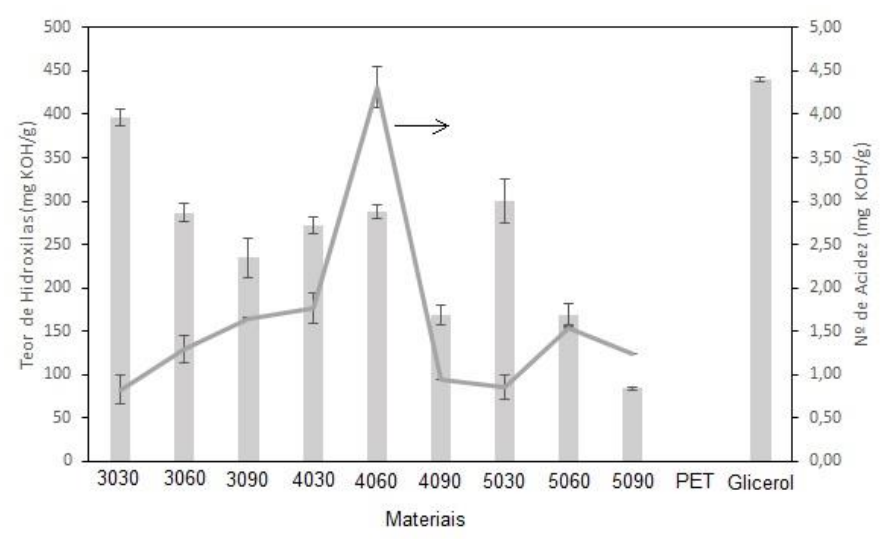

As análises térmicas dos novos polióis estão apresentadas na figura 4 logo abaixo. Observam-se dois eventos de degradação térmicas mais importantes, sendo que o primeiro relativo à presença de umidade de glicóis livres, com temperatura máxima de degradação em $200^{\circ} \mathrm{C}$. O segundo evento é referente ao PET e a novos poliésteres formados na recombinação do glicerol com o PET. Além disso, é possível observar que o primeiro evento de degradação térmica diminui à medida que o tempo de reação aumenta. Este fato pode ser devido a incorporação de glicerol nas porções de PET liquefeito. Com o aumento do tempo de reação é observado o aumento da estabilidade térmica e aumento da massa residual.

Figura 4 - Curvas TGA e DTG dos Polióis Formulados em Atmosfera de $\mathrm{N}_{2}$ a $60 \mathrm{~mL} / \mathrm{min}$ e taxa de aquecimento de $10^{\circ} \mathrm{C} / \mathrm{min}$.
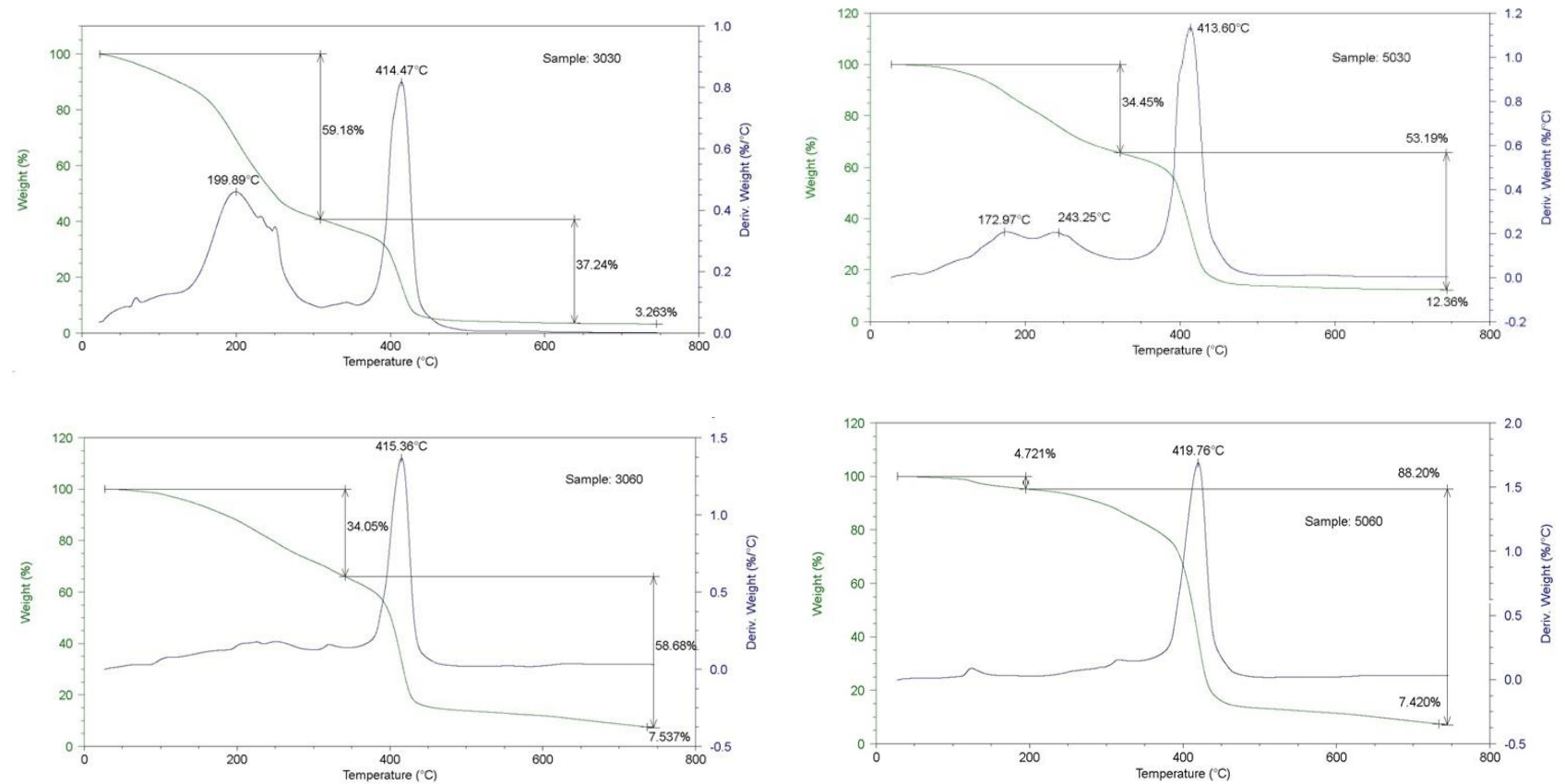



\section{CONCLUSÃO}

A glicerólise do PET se mostrou com grande eficiência possibilitando degradar e modificar em até $60 \%$ em massa do polímero. Desta forma, gerou uma família de novos polióis poliésteres, com teores de hidroxilas variados, com grande aplicabilidade em síntese de novos materiais poliméricos.

\section{REFERENCIAS}

ABIPET. Associação Brasileira da Indústria do PET. $10^{\circ}$ Censo da Reciclagem de PET no Brasil. Brasília, 2016.

ALMEIDA, I. S.; COSTA, I. M. D.; RIBEIRO, M. M. O.; HEINRICH, M.; MOREIRA, Q.; ARAUJO, P. J.; LEITE, M. S. Reciclagem de garrafas pet para fabricação de telhas. Cadernos de Graduação, v 1, nº 17, 2013.

FELIPE, T. R. Reciclagem de Garrafas PET para Utilização em Sistema de Telhas Sustentável. 2014. 79f. Tese (Mestrado Profissional em Processos Construtivos e Saneamento Urbano). Instituto de Tecnologia, Universidade Federal do Pará, Belém, Pará, 2014.

FONSECA, T. G.; ALMEIDA, Y. M. B.; VINHAS, G. M. Reciclagem Química do PET Pósconsumo: Caracterização Estrutural do Ácido Tereftálico e Efeito da Hidrólise Alcalina em Baixa Temperatura. Polímeros, vol.24, nº 5, p. 567-571, 2014.

ROMÃ̃, W.; SPINACÉ, M. A. S.; DE PAOLI, M. A. Poli(Tereftalato de Etileno), PET: Uma revisão sobre os processos de síntese, mecanismos de degradação e sua reciclagem. Polímeros, vol. 19, $\mathrm{n}^{\mathrm{o}}$ 2, 2009.

SANTOS, C.M.A.; GONÇALVES, A. C. R.; CINTRA, A. C.; DA SILVA, L. A.; ROSSI, A.; OLIVEIRA, H. P.; ALVES, V. A. Processo de reciclagem química de PET em meio alcalino: efeito da concentração do íon hidróxido, da cor do PET e do tempo de reação. Revista Matéria, v.23, nº 4, pp. 2018. 